\title{
Cleaning Method Affects Shrinkage Rate of Citrus Fruit
}

\author{
Robert D. Hagenmaier and Robert A. Baker \\ Citrus and Subtropical Products Laboratory, Agricultural Research Service, \\ U.S. Department of Agriculture, 600 Avenue S, Northwest, Winter Haven, \\ FL 33881
}

Additional index words. weight loss, fruit coating, fruit waxing, fruit cleansers, internal $\mathrm{CO}_{2}$, Citrus paradisi, Citrus hybrid, Citrus sinensis

\begin{abstract}
The shrinkage rate of 'Marsh' grapefruit (Citrus paradisi Macf.), 'Ambersweet' hybrid $[(C$. reticulata Blanco $\times C$. paradisi Macf. $\times C$. reticulata $) \times C$. sinensis $(\mathrm{L}$.) $\mathrm{Osb}$.] and 'Valencia' oranges [C. sinensis (L.) Osb.] was increased $50 \%$ to $150 \%$ by washing the fruit with rotary brushes, but was not changed by hand-washing the fruit with cellulose sponges. Internal $\mathrm{CO}_{2}$ increased using both washing methods. Waxed fruit obtained from five Florida packinghouses and cleaned with rotary brushes and waxed had shrinkage rates the same as those of nonwashed controls. Thus, controlling the washing process is important to minimize shrinkage of fresh citrus fruit.
\end{abstract}

For many years, citrus fruit have been prepared in packinghouses for the fresh-produce market by washing, treating with fungicide, and applying a coating (Kaplan, 1986; Smock, 1939). Currently, virtually all citrus fruit are coated, despite the flavor degradation that often results (Ahmad and Khan, 1987; Ben-Yehoshua, 1967; Cohen et al., 1990). Coated fruit commonly are said to be waxed, although many coatings contain no wax.

One reason for waxing citrus and other fruit is to reduce shrinkage due to water loss (Claypool, 1940; Hardenburg, 1967; Kaplan, 1986). However, before fruit are waxed they are washed, an operation that increases water loss. For example, washing navel oranges with brushes increased the shrinkage rate by $40 \%$ when measured after 1 week of storage at $24 \mathrm{C}$ (Millier and Brown, 1973). Waxing citrus fruit reportedly decreases the shrinkage rate to $70 \%$ of that of washed fruit (Hall, 1981). Washing and waxing together, according to these figures, would restore the shrinkage rate to that of nontreated, field-run fruit.

The present work-was undertaken to determine whether fruit washing could be controlled to minimize shrinkage, thus reducing dependence on wax for that purpose.

All fruit were freshly harvested Florida citrus. 'Marsh' grapefruit were harvested 21 Jan. 1992, 'Ambersweet' fruit were harvested 2 Nov. 1992, and 'Valencia' oranges were harvested in Apr. 1992. For laboratory and pilot-plant experiments, the fruit were divided randomly into treatment groups. 'Valencia'

\footnotetext{
Received for publication 3 Aug. 1992. Accepted for publication 19 Mar. 1993. Mention of a trademark or proprietary product is for identification only and does not imply a warranty or guarantee of the product by the U.S. Dept. of Agriculture over other products that also may be suitable. The cost of publishing this paper was defrayed in part by the payment of page charges. Under postal regulations, this paper therefore must be hereby marked advertisement solely to indicate this fact.
}

oranges from packinghouses were not randomized, although control and waxed fruit came from the same truckload. The packinghouses were located within $40 \mathrm{~km}$ of Winter Haven, Fla.

The fruit to be cleaned were soaked for $=1$ min in an alkylbenzene sulfonate standard biodegradable cleanser that also contained methyl-naphthalene sulfonates, chelating agents and silicates; a sooty-mold cleaner that contained these ingredients plus a nonionic surfactant; or SOPP soap, which contains sodium $o$-phenylphenate and unspecified surfactants. All cleansers were diluted with water according to the manufacturer's recommendations (FMC Corp., Lakeland, Fla.).

Fruit were washed with standard packinghouse-type brushes or cellulose sponges. Polypropylene brushes have triangular-shaped bristles of medium stiffness, and polyethylene brushes (Industrial Brush Corp., Eaton Park, Fla.) have triangular bristles and are the softest ones used in the citrus industry. Brush diameter was $12 \mathrm{~cm}$ and rotation was $22 \mathrm{rpm}$. During sponge-washing, the fruit were handcleaned for $5 \mathrm{sec} /$ fruit and, after 15 rein, cleaned once again the same way. After being washed, the fruit were rinsed for $1 \mathrm{sec}$ under water running at 12 liters $\cdot \min ^{-1}$.

Fruit cleanliness was determined visually. Fruit were rated clean if $<25 \mathrm{~mm}^{2}$ of the area appeared soiled.

Shrinkage was determined as weight loss over the specified period. The fruit were weighed at least three times after they had equilibrated to the $22 \mathrm{C}$ storage temperature. Shrinkage rates are reported in units of hourly weight loss as percent fruit weight.

Internal $\mathrm{CO}_{2}$ was determined by a gas chromatography (model 5890a; Hewlett-Packard, Avondale, Pa.) fitted with a $30-\mathrm{m} \times 0.53-\mathrm{mm}$ polystyrene column and thermal conductivity detector. Gas samples were withdrawn by syringe; the needle was inserted through the blossom end of the fruit into the core albedo. Respiration rate was measured at $22 \mathrm{C}$ for
10 fruit held in 8-liter flow-through containers fitted with condensing coils to control relative humidity at $50 \%$. Another set of coils controlled temperature. Air flowed into the chambers at $105 \mathrm{ml} \cdot \mathrm{min}^{-1}$. Respiration rate was determined after $4 \mathrm{~h}$ from steady-state $\mathrm{CO}$, concentration. Reported respiration rates (in milligrams of $\mathrm{CO}_{2}$ per kilogram per hour) are means of two determinations.

Air flux measures the tendency of a piece of fruit to allow air to pass through openings in its epidermis, a method recently developed (Hagenmaier and Baker, 1993). Briefly, a syringe needle is inserted 1 to $3 \mathrm{~cm}$ deep through the blossom end of the fruit into the albedo. After sealing the needle shaft against the fruit epidermis with 5-min epoxy glue, air flow into the needle is measured under applied hydrostatic pressure. Air flow and pressure are measured by movement and height of the meniscus in a manometer. Values are reported as flux at a hydrostatic pressure of $75 \mathrm{~cm}$ water (0.074 bar).

Statistical analyses are based on Student's t tests at $P \leq 0.05$; significant differences are reported at the computed level of significance.

Brush-washed fruit. Preliminary results indicated that brush-washed 'Valencia' oranges lost weight at $0.10 \%$ per h compared to $0.04 \%$ for nonwashed controls ( 1 to $2 \mathrm{~min}$ washing with polypropylene brushes, nine fruit per treatment).

Grapefruit washed the same way had a shrinkage rate $\approx 50 \%$ higher than that of the controls (Table 1). Internal $\mathrm{CO}_{2}$ after storage for 7 days was higher for the washed fruit $(P \leq$ 0.001 ). The air flux was virtually unchanged, a result suggesting that washing did not markedly change the condition of the openings

Table 1. Shrinkage rates' and internal gases of 'Marsh' grapefruit' as effected by washing 1 to 2 min with polypropylene brushes and SOPP soap. Data were obtained after 1 week of storage at $22 \mathrm{C}$ and $50 \%$ relative humidity.

\begin{tabular}{lccc}
\hline & $\begin{array}{c}\text { Shrinkage } \\
\text { rate } \\
(\% \text { per } \mathrm{h})\end{array}$ & $\begin{array}{c}\text { Internal } \\
\mathrm{CO}_{2} \\
(\%)\end{array}$ & $\begin{array}{c}\text { Air flux } \\
\left(\mathrm{ml} \cdot \mathrm{min}^{-1}\right)\end{array}$ \\
Treatment & $\mathbf{0 . 0 1 9}$ & $\mathbf{1 . 0}$ & $\mathbf{6 . 2}$ \\
Control & 0.029 & 1.6 & 4.6 \\
Washed & 0.001 & $\mathbf{0 . 0 7}$ & $\mathbf{0 . 9}$
\end{tabular}

${ }^{\mathrm{z}}$ All data are from individual measurements on 22 fruit. For difference in shrinkage rates and internal $\mathrm{CO}_{2}, P \leq 0.0001$

Mean weight was $350 \mathrm{~g} /$ fruit; fruit were harvested 21 Jan. 1992 by clipping stems.

Table 2. Shrinkage rate' and internal $\mathrm{CO}_{2}$ of 'Ambersweet' oranges cleaned for $30 \mathrm{sec}$ with two types of brushes and SOPP soap and then stored at $20 \mathrm{C}$ and $75 \%$ relative humidity.

\begin{tabular}{lcccc}
\hline \hline \multirow{2}{*}{$\begin{array}{l}\text { Brush } \\
\mathrm{t} \mathrm{y} \mathrm{p} \mathrm{e}\end{array}$} & $\begin{array}{c}\text { Shrinkage } \\
\text { rate }\end{array}$ & \multicolumn{2}{c}{$\begin{array}{c}\text { Internal } \mathrm{CO}_{2}{ }^{\mathrm{y}} \\
\text { (\%) }\end{array}$} \\
\cline { 3 - 5 } None (control) & 0.0087 & days & days \\
Polyethylene & 0.0120 & 1.4 & 1.0 \\
Polypropylene & 0.0141 & 2.0 & 1.7 \\
\hline
\end{tabular}

${ }^{2}$ Rate of weight loss during third day of storage. Mean of four samples per treatment, five fruit per sample. LSD $(P \leq 0.05)$ is $0.001 \%$ per $h$.

${ }^{y}$ Means for five fruit per treatment; $\mathrm{LSD}=0.05$. 
(stomates, lenticels, and those caused by injuries) in the fruit surface.

Brush-washed 'Ambersweet' fruit had a shrinkage rate $\approx 60 \%$ higher than that of the controls when cleaned $30 \mathrm{sec}$ with polypropylene bristles, but only $\approx 40 \%$ higher when cleaned with polyethylene bristles, which are softer (Table 2).

The shrinkage rate of 'Valencia' oranges brush-washed and waxed was not markedly different from that of the nonwashed controls (Table 3). Thus, applying coatings compensated for any increase in shrinkage rate caused by washing. The same result was found for 'Valencia' oranges coated with polyethylene wax in three Israeli packinghouses (BenYehoshua, 1967).

Sponge-washed fruit. To determine the properties of fruit washed with minimum abrasion, fruit were sponge-washed. The shrinkage rate of 'Valencia' oranges was unchanged by washing in this manner (Table 4). Fruit

Table 3. Shrinkage rates of 'Valencia' oranges ${ }^{2}$ from five packinghouses.

\begin{tabular}{lccc}
\hline \hline & & \multicolumn{2}{c}{$\begin{array}{c}\text { Shrinkage rate } \\
(\% \text { per h) }\end{array}$} \\
\cline { 3 - 4 } Packing- & $\begin{array}{c}\text { Fruit } \\
\text { house }\end{array}$ & $\begin{array}{c}\text { Nonwashed, } \\
\text { coating }\end{array}$ & $\begin{array}{c}\text { Washed, } \\
\text { nonwaxed } \\
\text { waxed }\end{array}$ \\
\hline $\mathrm{A}$ & $\begin{array}{c}\text { Shellac- } \\
\text { wood resin }\end{array}$ & 0.044 & 0.043 \\
B & $\begin{array}{c}\text { Coumarone- } \\
\text { indene }\end{array}$ & 0.045 & 0.046 \\
C & $\begin{array}{c}\text { Coumarone- } \\
\text { indene }\end{array}$ & 0.047 & 0.034 \\
D & Resin wax & 0.037 & 0.032 \\
E & Shellac & 0.052 & 0.046 \\
Means & & 0.045 & 0.040
\end{tabular}

${ }^{2}$ Harvested 15-16 Apr. 1992.

${ }^{y}$ Measured as rate of weight loss after 1 week of storage at $22 \mathrm{C}$ at $50 \% \pm 10 \%$ relative humidity. Five samples per treatment, 800 to $1200 \mathrm{~g}$ fruit/sample. SE $=0.0016 \%$ per $\mathrm{h}$.

Table 4. Shrinkage ratio, internal $\mathrm{CO}_{2}$, and cleanliness of sponge-washed 'Valencia' oranges heavily contaminated with sooty mold.

\begin{tabular}{|c|c|c|c|}
\hline Cleanser & $\begin{array}{c}\text { Shrinkage } \\
\text { ratio }^{y}\end{array}$ & $\begin{array}{l}\text { Internal }^{z} \\
\mathrm{CO}_{2}(\%)\end{array}$ & $\begin{array}{c}\text { Clean } \\
\text { fruit }^{x}(\%)\end{array}$ \\
\hline None (control) & 7.00 & 3.6 & 1 \\
\hline SOPP Soap & 0.98 & 7.0 & 62 \\
\hline Sooty mold & 0.97 & 6.6 & 47 \\
\hline $\mathrm{AS}^{\mathrm{w}}$ & 1.00 & 5.2 & 84 \\
\hline$+250 \mathrm{ppm} \mathrm{Cl}$ & 1.00 & 5.8 & 85 \\
\hline
\end{tabular}

${ }^{2}$ Twenty-seven trials for control, 10 for washed fruit. $\mathrm{SE}=0.04$.

${ }^{\dot{y}}$ Ratio of rate of weight loss at $20 \mathrm{C}$ to that of randomized controls from the same source. Ten samples per treatment, 800 to $1200 \mathrm{~g}$ fruit/sample. SE $=0.04$.

xMean of two trials (five trials for control), 25 fruit/ trial. $\mathrm{SE}=0.1$

"AS = alkylbenzene sulfonate. cleanliness was highest with alkylbenzene sulfonate cleanser. Internal $\mathrm{CO}_{2}$ was elevated by all cleansers tested (et< 0.01 ).

A similar effect on shrinkage was observed for 250 'Valencia' oranges washed with alkylbenzene sulfonate cleanser spiked with $250 \mathrm{ppm} \mathrm{Cl}_{2}$ (from $\mathrm{NaOCl}$ ) (Fig. 1). The sponge-washed fruit initially lost weight faster than the controls and, thus, had a shrinkage ratio $>1.0$. After storage for 7 days, however, the shrinkage rates were virtually the same.

The washed fruit had markedly higher internal $\mathrm{CO}_{2}$ (Fig. $1 ; \alpha \leq 0.001$ ). Internal $\mathrm{CO}_{2}$ was elevated by all washing processes used in this study (Tables 1,2 , and 4). Internal $\mathrm{CO}_{2}$ is elevated further by waxing washed citrus fruit (Ben-Yehoshua, 1967; Cohen et al., 1990; Hagenmaier and Baker, 1993). Thus, washing and waxing hinder $\mathrm{CO}_{2}$ exchange.

The respiration rate was slightly higher in sponge-washed fruit after 2 days of storage; but, when stored $>2$ days, respiration rate decreased (Fig. 1). Millier and Brown (1973) observed a temporarily higher respiration rate for brush-washed oranges, possibly caused by extra handling during washing (Vines et al., 1968)

Air flux through the peel decreased with storage time and was lower for the spongewashed than the control fruit. The median
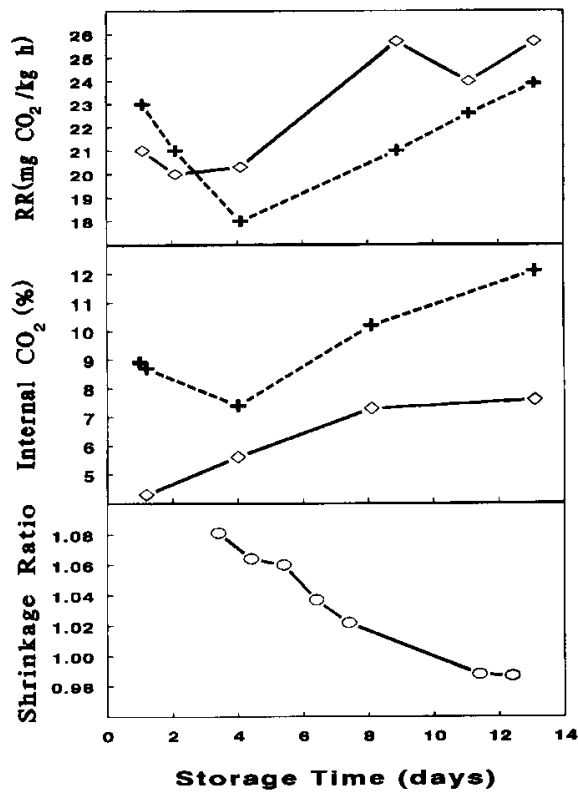

Fig. 1. Respiration rate (RR), internal $\mathrm{CO}_{2}$, and shrinkage ratio of 'Valencia' oranges harvested $30 \mathrm{Apr}$. and stored at 22C. RR is based on two trials, 10 fruit/trial; internal $\mathrm{CO}_{2}$ is the mean of 10 samples. (+) Washed, $(0)$ control. Shrinkage ratio $(O)$ equals weight-loss rate of washed divided by that of control, based on 24 samples/ treatment, 800 to $1200 \mathrm{~g}$ fruit/sample. values after 4.8. and 13 days of storage were $1.1,0.8$, and $0.5 \mathrm{ml} \cdot \mathrm{min}^{-1}$ for control\&d 0.5 , 0.3 , and $0.2 \mathrm{ml} \cdot \mathrm{min}^{-1}$ for sponge-washed fruit, respectively (10 samples per treatment).

Of the 250 sponge-washed fruit, $73 \%$ was acceptably clean, compared to an average of 93\% of washed and waxed fruit. Thus, spongewashing was not as effective as methods currently used in the citrus-processing industry. More thorough washing with sponges might have resulted in increased weight loss.

Shrinkage rate was virtually the same for nonwashed controls, fruit washed and waxed in packinghouses, and sponge-washed fruit. In contrast, brush-washed fruit had higher shrinkage rates. These results suggest that controlling abrasion during washing can yield citrus fruit with less shrinkage than that of fruit processed by present methods. Unfortunately, literature on postharvest citrus treatment generally does not mention cleansers, brush types, or brushing time; thus, it is of little value as an information base for controlling washing.

Whether it is possible to clean fruit to market conditions with minimal abrasion has not yet been demonstrated. However, results point to that possibility.

\section{Literature Cited}

Ahmad, M. and I. Khan. 1987. Effect of waxing and cellophane lining on chemical quality indices of citrus fruit. Plant Foods for Human Nutr. 37:4757

Ben-Yehoshua, S. 1967. Some physiological effects of various skin coatings on orange fruit. Israel J. Agr. Res. 17:17-27.

Claypool, L.L. 1940. The waxing of deciduous fruits. Proc. Amer. Soc. Hort. Sci. 37:443-447.

Cohen, E., Y. Shalom, and I. Rosenberger. 1990. Postharvest ethanol buildup and off-flavor in 'Murcott' tangerine fruits. J. Amer. Soc. Hort. Sci. 115:775-778.

Hagenmaier, R.D. and R.A. Baker. 1993. Reduction in gas exchange of citrus fruit by wax coatings. J. Agr. Food Chem. 41:283-287.

Hall, D.J. 1981. Innovations in citrus waxing-An overview. Proc. Fla. State Hort. Soc. 94:258263.

Hardenburg, R.E. 1967. Wax and related coatings for horticultural products. U.S. Dept. Agr. Bul. ARS-51-15. p. 1-15.

Kaplan, H.J. 1986. Washing, waxing and coloradding, p. 379-395. In: W.F. Wardowski, S. Nagy, and W. Grierson (eds.). Fresh citrus fruits. AVI, Westport, Conn.

Millier, W.F. and G.K. Brown. 1973. Citrus fruit appearance, weight loss, and internal condition inferences for mechanical harvesting. U.S. Dept Agr. Tech. Bul. ARS-W-5.

Smock, R.M. 1939. Wax emulsions for deciduous fruits. Amer. Fruit Grower 59:5-15.

Vines, H. M., W. Grierson, and G.J. Edwards. 1968. Respiration, internal atmosphere and ethylene evolution of citrus fruit. Proc. Amer. Soc. Hort. Sci. 92:227-234. 